Research

\title{
Tenofovir treatment augments anti-viral immunity against drug-resistant SIV challenge in chronically infected rhesus
} macaques

\author{
Karin J Metzner ${ }^{1,5}$, James M Binley², Agegnehu Gettie ${ }^{3}$, Preston Marx ${ }^{3}$, \\ Douglas F Nixon ${ }^{4}$ and Ruth I Connor*1,6
}

\begin{abstract}
Address: ${ }^{1}$ Aaron Diamond AIDS Research Center and The Rockefeller University, New York, NY 10016, USA, ${ }^{2}$ Torrey Pines Institute for Molecular Studies, San Diego, CA 92121, USA, ${ }^{3}$ Tulane Regional Primate Research Center and Department of Tropical Medicine, Tulane University Health Sciences Center, Covington, LA 70433, USA, ${ }^{4}$ University of California, San Francisco, Department of Medicine, Division of Experimental Medicine, San Francisco, CA 94110, USA, 5 University of Erlangen-Nuremberg, Institute of Clinical and Molecular Virology, Schlossgarten 4, Erlangen, 91054, Germany and ${ }^{6}$ Department of Microbiology and Immunology, HB7556, Dartmouth-Hitchcock Medical Center, One Medical Center Drive, NH 03756, Lebanon

Email: Karin J Metzner - Karin.Metzner@viro.med.uni-erlangen.de; James M Binley - jbinley@tpims.org; Agegnehu Gettie - Agettie@aol.com; Preston Marx - pmarx@tulane.edu; Douglas F Nixon - douglas.nixon@ucsf.edu; Ruth I Connor* - Ruth.I.Connor@Dartmouth.edu

* Corresponding author
\end{abstract}

Published: 21 December 2006

Retrovirology 2006, 3:97 doi:10.1186/1742-4690-3-97

This article is available from: http://www.retrovirology.com/content/3/l/97

(C) 2006 Metzner et al; licensee BioMed Central Ltd.

This is an Open Access article distributed under the terms of the Creative Commons Attribution License (http://creativecommons.org/licenses/by/2.0), which permits unrestricted use, distribution, and reproduction in any medium, provided the original work is properly cited.

\begin{abstract}
Background: Emergence of drug-resistant strains of human immunodeficiency virus type I (HIV-I) is a major obstacle to successful antiretroviral therapy (ART) in HIV-infected patients. Whether antiviral immunity can augment ART by suppressing replication of drug-resistant HIV-I in humans is not well understood, but can be explored in non-human primates infected with simian immunodeficiency virus (SIV). Rhesus macaques infected with live, attenuated SIV develop robust SIV-specific immune responses but remain viremic, often at low levels, for periods of months to years, thus providing a model in which to evaluate the contribution of antiviral immunity to drug efficacy. To investigate the extent to which SIV-specific immune responses augment suppression of drug-resistant SIV, rhesus macaques infected with live, attenuated SIVmac239 $\Delta$ nef were treated with the reverse transcriptase (RT) inhibitor tenofovir, and then challenged with pathogenic SIVmac055, which has a five-fold reduced sensitivity to tenofovir.

Results: Replication of SIVmac055 was detected in untreated macaques infected with SIVmac239 $\Delta$ nef, and in tenofovir-treated, naïve control macaques. The majority of macaques infected with SIVmac055 experienced high levels of plasma viremia, rapid $\mathrm{CD}^{+} \mathrm{T}$ cell loss and clinical disease progression. By comparison, macaques infected with SIVmac239 $\Delta$ nef and treated with tenofovir showed no evidence of replicating SIVmac055 in plasma using allele-specific real-time PCR assays with a limit of sensitivity of $50 \mathrm{SIV}$ RNA copies/ml plasma. These animals remained clinically healthy with stable $C D 4^{+} \mathrm{T}$ cell counts during three years of follow-up. Both the tenofovir-treated and untreated macaques infected with SIVmac239 $\Delta$ nef had antibody responses to SIV gPI30 and p27 antigens and SIV-specific CD8 ${ }^{+} \mathrm{T}$ cell responses prior to SIVmac055 challenge, but only those animals receiving concurrent treatment with tenofovir resisted infection with SIVmac055.

Conclusion: These results support the concept that anti-viral immunity acts synergistically with ART to augment drug efficacy by suppressing replication of viral variants with reduced drug sensitivity. Treatment strategies that seek to combine immunotherapeutic intervention as an adjunct to antiretroviral drugs may therefore confer added benefit by controlling replication of HIV-I, and reducing the likelihood of treatment failure due to the emergence of drug-resistant virus, thereby preserving treatment options.
\end{abstract}




\section{Background}

Initiation of antiretroviral therapy (ART) in patients with HIV-1 infection can rapidly reduce plasma viremia, bolster immune responses, and improve clinical outcome [13]. Despite significant progress in the clinical management of HIV-1 infection, the therapeutic efficacy of ART is often undermined by incomplete suppression of virus replication and the emergence of drug-resistant HIV-1 [4]. Drug-resistant strains of HIV-1 harbor mutations that can negatively impact viral fitness, but these viruses gain a replicative advantage in the presence of drug and can be associated with treatment failure and clinical progression $[5,6]$. Moreover, drug-resistant HIV-1 can be transmitted to treatment-naïve individuals, thereby limiting the range of therapeutic options available to these patients $[7,8]$.

The extent to which HIV-specific immune responses suppress the emergence of drug-resistant strains is not well understood, but may be influenced by immune recognition of epitopes containing key resistance mutations. $\mathrm{CD}^{+} \mathrm{T}$ cells from individuals harboring multi-drug-resistant HIV-1 still respond in vitro to proteins and peptides containing commonly found drug resistance mutations $[9,10]$, suggesting that immune recognition is adaptive and responsive to the emergence of drug-resistant virus. Whether these responses control replication of drugresistant HIV-1 in vivo, and whether they can be induced in HIV-infected patients as a protective measure against the emergence of drug-resistant viral variants is unknown.

The concept that drug efficacy can be augmented by strong antiviral immune responses is compelling, and has led to efforts to stimulate antiviral immunity in HIV-infected patients on ART. Various immunotherapeutic strategies including structured treatment interruptions, therapeutic immunization, and immunomodulatory agents have been explored with limited success to date [11], and serve to highlight the complexity of the interaction between host immunity, virus replication and drug efficacy.

In this respect, animal studies using SIV infection of nonhuman primates provide a useful tool to shed light on the mechanisms of immune-mediated control of infection, the impact of antiretroviral drugs on virus replication [12], and the emergence and evolution of drug-resistant variants [13]. SIV infection in rhesus macaques shares many of the immunopathogenic features of HIV-1 infection in humans, and this model has been used to evaluate the contribution of antiviral immune responses to suppression of virus replication during ART intervention. In vivo depletion of $\mathrm{CD}^{+} \mathrm{T}$ cells in SIV-infected macaques receiving treatment with the reverse transcriptase (RT) inhibitor tenofovir \{9-[2-(phosphonomethoxy)propyl] adenine, PMPA $\}$ leads to an increase in viremia, providing direct evidence that these cells significantly contribute to the success of tenofovir in suppressing replication of virulent SIV [14].

The notion that antiviral immune responses play a critical role in augmenting the efficacy of ART is amenable to further study in rhesus macaques infected with live, attenuated SIV, in which broad SIV-specific cellular and humoral immune responses are induced, and can confer robust protection against exogenous SIV challenge [15]. Interestingly, antiviral immunity in these animals fails to fully control replication of the endogenous attenuated SIV strain and infected macaques remain continuously viremic for periods of months to years [16]. In vivo depletion of $\mathrm{CD} 8^{+} \mathrm{T}$ cells in macaques infected with live, attenuated SIV leads to a marked increase in viremia indicating a critical role for these cells in controlling virus replication [17]. In the absence of drug intervention, pathogenic sequelae can develop in both neonatal [18] and adult [19] animals infected with live, attenuated SIV, mirroring in certain aspects the clinical progression of chronic HIV-1 infection in humans, including increasing viral burden and progressive loss of $\mathrm{CD} 4+\mathrm{T}$ cells.

The immunologic and virologic features of macaques infected with live, attenuated SIV, typified by low-level viremia and strong SIV-specific humoral and cellular immune responses, provide a unique opportunity to examine the contribution of SIV-specific immunity to augmenting ART and suppressing replication of drugresistant virus during chronic infection. Here, we report on treatment of macaques chronically infected with SIVmac239 3 nef with a short-term regimen of tenofovir and challenged with drug-resistant SIV. Our results indicate that tenofovir given to macaques with established anti-viral immunity can prevent replication of drug-resistant virus in the setting of chronic SIV infection.

\section{Results \\ Effect of tenofovir on SIVmac055 challenge of naïve rhesus macaques}

To evaluate the dose and replicative capacity of SIVmac055 in the presence of tenofovir, four drug-naïve adult rhesus macaques were subcutaneously given tenofovir daily for 4 weeks prior to intravenous inoculation with $10^{4} \mathrm{TCID}_{50}$ of SIVmac055. Tenofovir treatment was continued for an additional 2 weeks after SIVmac055 inoculation, and virus replication, CD4/CD8 T cell counts, and clinical adverse events were monitored at regular intervals (Fig. 1). All of the macaques had $\mathrm{CD}^{+}$and $\mathrm{CD} 8^{+} \mathrm{T}$ cell counts within the normal range at baseline (Table 1). Tenofovir treatment was well tolerated in the macaques and no sustained changes in $\mathrm{CD} 4^{+}$and $\mathrm{CD} 8^{+} \mathrm{T}$ cell counts were observed during the treatment intervention, with the exception of one macaque (P679) that experienced a transient drop in $\mathrm{CD} 4{ }^{+} \mathrm{T}$ cell counts. None of the macaques 
exhibited any serious adverse events associated with tenofovir treatment.

Quantification of SIV RNA by real-time PCR revealed the presence of SIVmac055 RNA in the plasma of all 4 macaques within 3 to 14 days of inoculation (Fig. 1A). Peak viremia occurred between days 14 and 42 post-infection with maximal plasma viral loads ranging from $2-6.3$ $\times 10^{5}$ SIV RNA copies/ml plasma. Viral loads remained elevated, and 3 of 4 macaques developed symptoms of simian AIDS and were euthanized within 12 to 15 months after infection. These macaques experienced a significant decline in $\mathrm{CD}^{+}{ }^{+} \mathrm{T}$ cells associated with SIVmac055 infection (Fig. 1B) and displayed typical clinical and pathological features consistent with simian AIDS. The remaining macaque (P804) became infected with SIVmac055, but was able to control the infection and $\mathrm{CD}^{+} \mathrm{T}$ cells remained stable in this animal for over a year (Fig. 1B). However, macaque P804 was subsequently euthanized due to severe self-inflicted trauma. Upon autopsy, no signs of simian AIDS were found, although tissues were not examined for the presence of SIV. All four animals developed SIV-specific anti-gp130 and anti-p27 antibodies, but no significant differences in antibody titers were seen between the three macaques that developed simian AIDS and macaque P804 who appeared to control SIVmac055 infection (Fig. 2A and 2B). Taken together, these results demonstrate that SIVmac055, when inoculated intravenously at a dose of $10^{4} \mathrm{TCID}_{50} / \mathrm{ml}$, is able to infect and replicate in the majority of rhesus macaques receiving concurrent antiretroviral treatment with tenofovir.

\section{Analyses of SIVmac055 nucleotide sequences in control rhesus macaques}

Five-fold resistance to tenofovir in vitro is associated with a K65R mutation, and additional compensatory mutations, in the RT gene of SIVmac055 [20]. To determine whether these mutations were present in virus isolated from the tenofovir-treated macaques, plasma viral RNA was reverse transcribed, amplified with oligonucleotides spanning part of the SIV pol gene, and the PCR products directly sequenced. Five mutations in RT are reported for SIVmac055: K65R, N69T, R82K, A158S, and S211N [20]. Sequence analyses of the SIVmac055 stock used in our experiments revealed these five mutations and an additional mutation (K64R) present in a minor population of variants (data not shown). All five mutations associated with tenofovir resistance were identified in virus sequences from the tenofovir-treated macaques infected with SIVmac055, and these mutations were stable over time (Table 2). In all animals, a mixed population (S211N/S211S) was found at week 35 post-infection and persisted thereafter. The K64R mutation was present in three animals at week 2 post-infection as mixed popula- tion $(\mathrm{K} 64 \mathrm{R} / \mathrm{K})$. By week 35, the K64R mutation emerged as the major population in three infected animals.

\section{Administration of tenofovir to macaques with chronic SIVmac239 Anef infection}

Five adult rhesus macaques were infected with SIVmac239 nef approximately three years prior to initiation of this study [16]. All five were shown to resist pathogenic SIVmac251 challenge with no evidence of SIVmac251 RNA or DNA in either plasma or lymph nodes over a 3-year follow-up period [16]. However, all the animals remained intermittently viremic with low levels of plasma SIVmac239 $\Delta$ nef detected throughout the followup period, consistent with a failure to fully suppress replication of the original infecting strain. Each of the animals developed robust SIV-specific humoral and cellular immune responses, which may have contributed to protection from exogenous SIVmac251 challenge, but these responses were insufficient to prevent ongoing replication of the endogenous attenuated virus. All of the SIVmac2394nef-infected macaques had CD $4{ }^{+}$and $\mathrm{CD} 8{ }^{+} \mathrm{T}$ cell counts within the normal range, and plasma viral loads ranging from $<50-3.5 \times 10^{3}$ SIV RNA copies $/ \mathrm{ml}$ plasma immediately prior to initiation of this study (Table 1).

To evaluate the effects of tenofovir in macaques infected with SIVmac239 $\Delta$ nef, 3 of 5 macaques were given daily subcutaneous injections of tenofovir at a dose of $30 \mathrm{mg} /$ $\mathrm{kg}$ for 4 weeks. Previous studies have demonstrated significant suppression of virulent SIV during both acute $[21,22]$ and chronic $[20,23]$ infection in both juvenile and adult macaques at similar dosing levels. In our hands, tenofovir rapidly reduced plasma viral load within $24 \mathrm{hrs}$ of initiation of treatment in an adult macaque infected with pathogenic SIVmac251 (1484, Fig. 3A). The same dosing regimen was also found to reduce replication of SIVmac239 $\Delta$ nef by $2 \operatorname{logs}_{10}$ (1498, Fig. 3B), indicating that tenofovir is effective at inhibiting replication of nefdeleted SIV. Less pronounced changes in viral load were observed in two other macaques with intrinsically low baseline levels of plasma SIVmac2394nef RNA (1488, 1514) (Fig. 4). Two additional macaques infected with SIVmac239 nef $(1494,1512)$ did not receive tenofovir and served as untreated controls. Plasma viremia in these animals ranged from $<50$ to $1.7 \times 10^{3}$ SIV RNA copies $/ \mathrm{ml}$ plasma at baseline with no consistent changes in viral load over the 4-week period corresponding to the interval of tenofovir treatment (Fig. 4).

\section{Outcome of challenge with drug-resistant SIVmac055}

After 4 weeks of drug intervention, the tenofovir-treated and control macaques were intravenously challenged with $10^{4} \mathrm{TCID}_{50}$ of SIVmac055. Replication of SIVmac055 and SIVmac239 $\Delta$ nef were monitored by three methods: 1 ) 

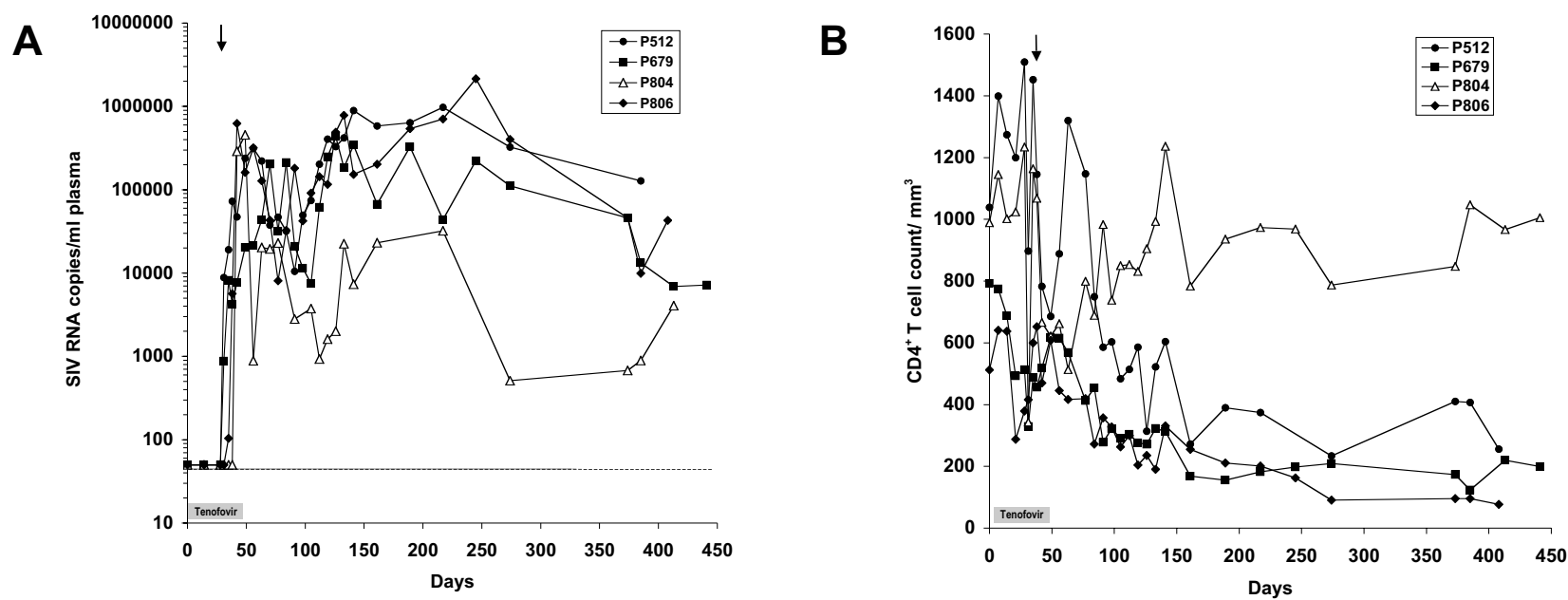

Figure I

Pre-treatment of naïve rhesus macaques with tenofovir and subsequent infection with SIVmac055. Adult rhesus macaques were treated for 4 weeks with tenofovir at a dose of $30 \mathrm{mg} / \mathrm{kg}$ body weight, and then inoculated intravenously with SIVmac055 on day 28 (arrow). Tenofovir treatment was continued for an additional 2 weeks after SIVmac055 infection. Virus replication and $C D 4^{+} T$ cell counts were monitored for $>$ I year of follow-up. (A) Plasma viral load was measured by real-time PCR with a sensitivity of 50 SIV RNA copies/ml, (B) CD4+ T-cell counts.

allele-specific real-time PCR with molecular beacons to discriminate between the two viruses, 2) PCR to detect wild-type and nef-deleted alleles, and 3) PCR amplification and direct sequencing of regions of the SIV pol gene to identify drug resistance mutations within RT.

Evaluation of virus replication in the two untreated control macaques $(1494,1512)$ revealed the presence of SIVmac055 in both animals within several weeks of intravenous challenge (Table 3 ). Sequence and PCR analyses of nef alleles demonstrated that, in the first 2 weeks after challenge, the replicating viral population in macaque 1494 was predominantly SIVmac239 $\Delta$ nef. However, 6 to 7 weeks after challenge, viral RNA sequences consistent with SIVmac055 were detected. By 10 weeks and thereafter, viral RNA contained wild-type nef alleles and SIVmac239 $\Delta$ nef pol sequences suggesting that virus recombination between SIVmac055 and SIVmac239 $\Delta$ nef had occurred in this animal. To confirm these results, a $7.0 \mathrm{~kb}$ fragment (nucleotides 2904 to 9894 [24]) span-

Table I: Immunization history and baseline characteristics of rhesus macaques prior to tenofovir treatment

\begin{tabular}{|c|c|c|c|c|c|c|c|}
\hline \multirow[b]{2}{*}{ Macaque } & \multirow[b]{2}{*}{ SIV infection ${ }^{a}$} & \multirow[b]{2}{*}{$\begin{array}{c}\text { Protection against } \\
\text { SIVmac25 I chal- } \\
\text { lenge }^{\text {b }}\end{array}$} & \multirow{2}{*}{$\begin{array}{c}\text { SIVmac239 } 2 \text { nef } \\
\text { proviral load } \\
\text { DNA copies/1 } 0^{6} \\
\text { genomic equivalentsc }\end{array}$} & \multirow[b]{2}{*}{ Tenofovir } & \multicolumn{2}{|c|}{ Lymphocyte counts $\left(\text { cells } / \mathrm{mm}^{3}\right)^{d}$} & \multirow{2}{*}{$\begin{array}{l}\text { SIVmac239 } 23 \text { nef } \\
\text { plasma viral loade } \\
\text { (RNA copies } / \mathrm{ml} \\
\text { plasma }\end{array}$} \\
\hline & & & & & $\mathrm{CD4}^{+} \mathrm{T}$ cells & $\mathrm{CD8}^{+} \mathrm{T}$ cells & \\
\hline $\mathrm{P} 5 \mathrm{I} 2$ & - & ND & ND & + & 1039 & 705 & $<50$ \\
\hline P679 & - & ND & ND & + & 793 & 609 & $<50$ \\
\hline P804 & - & ND & ND & + & 989 & 847 & $<50$ \\
\hline P806 & - & ND & ND & + & 512 & 371 & $<50$ \\
\hline 1494 & 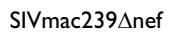 & + & $29 \pm 23$ & - & $558 \pm 21$ & $520 \pm 75$ & $1.5 \times 10^{3}$ \\
\hline 1512 & 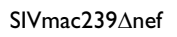 & + & $14 \pm 9$ & - & $868 \pm 207$ & $864 \pm 269$ & $5.5 \times 10^{2}$ \\
\hline 1488 & 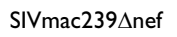 & + & $66 \pm 41$ & + & $725 \pm 82$ & $753 \pm 208$ & $<50$ \\
\hline 1498 & 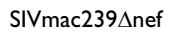 & + & $12 \pm 10$ & + & $669 \pm 61$ & $|47| \pm 343$ & $3.5 \times 10^{3}$ \\
\hline 1514 & 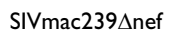 & + & $291 \pm 123$ & + & $703 \pm 180$ & $963 \pm 342$ & $<50$ \\
\hline
\end{tabular}

a Macaques were infected with SIVmac239 $\Delta$ nef approximately 3 years prior to initiation of this study [16]

b Challenge with SIVmac25I was carried out from 10 and 25 weeks after immunization with SIVmac239 $\Delta$ nef [16]

c Mean \pm standard deviation of 5-7 time points within 2.5 years before administration of tenofovir

d Mean \pm standard deviation of days $-14,-6$ and 0 before administration of tenofovir

e Day 0 before administration of tenofovir 

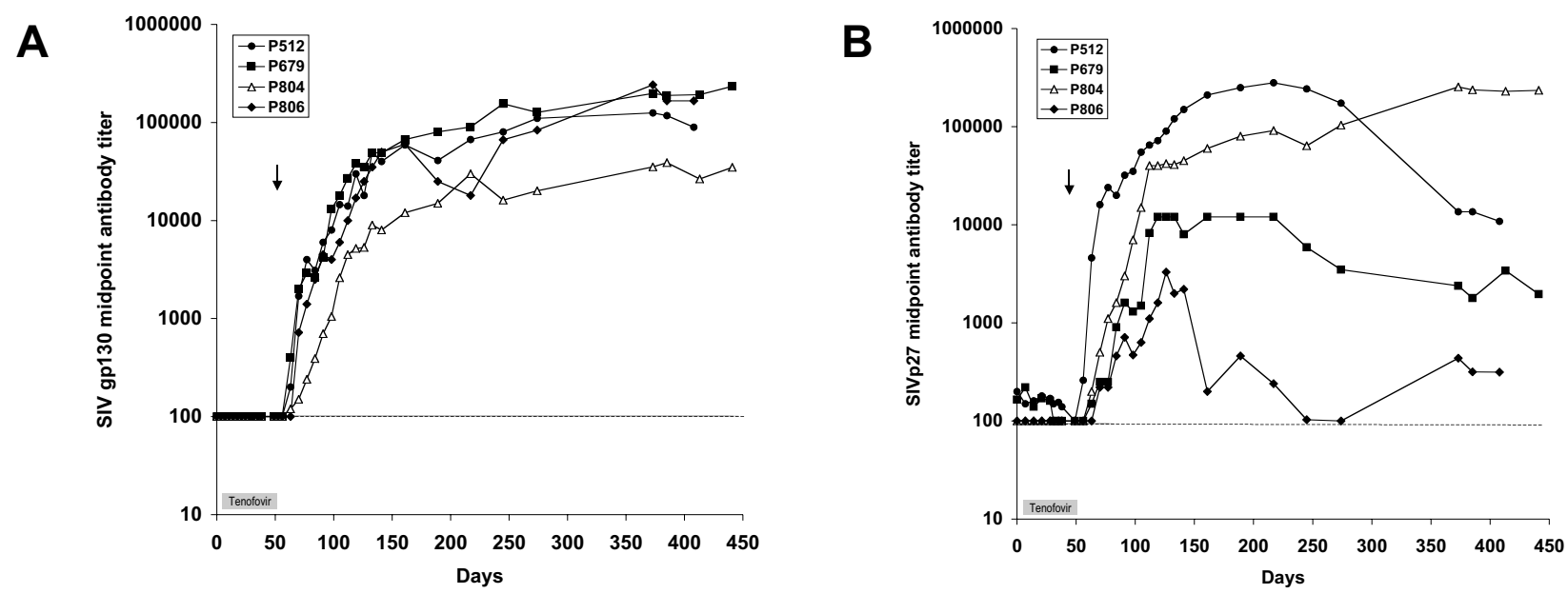

\section{Figure 2}

SIV-specific antibody responses in tenofovir-treated macaques infected with SIVmac055. Plasma antibody titers to (A) SIV gPI30 and (B) SIV p27 were measured during tenofovir treatment (days 0-42) and after challenge with SIVmac055 (day 28, arrow). Data is expressed as the midpoint antibody titer based on serial titration of plasma and antibody detection by antigen-specific ELISA [16, 4I].

ning SIV pol through nef was cloned and sequenced. Multiple clones demonstrated SIVmac239 pol sequences and wild-type nef alleles (Table 3). Macaque 1494 was euthanized approximately 2 years after SIVmac055 challenge with clinical symptoms of severe enterocolitis and diarrhea, and marked loss of CD4+ $\mathrm{T}$ cells (Fig. 5A).

The other untreated macaque (1512) also had evidence of SIVmac055 infection with low levels of virus replication. Sequenced pol genes revealed drug resistance mutations in
RT consistent with SIVmac055 (Table 3). An additional K64R mutation in RT was also found. Despite low levels of viral replication, $\mathrm{CD} 4^{+} \mathrm{T}$ cells steadily declined after 8 months (Fig. 5A), and this macaque died approximately 18 months after SIVmac055 challenge due to a lung infarction caused by massive thrombosis.

Three additional macaques infected with SIVmac239 $\Delta$ nef $(1488,1498,1514)$ were treated with tenofovir as described and monitored for viral replication after chal-

Table 2: Mutations in plasma SIV RT from rhesus macaques infected with SIVmac055

\begin{tabular}{|c|c|c|c|c|c|c|c|c|}
\hline \multirow[b]{2}{*}{ Macaque } & \multirow[b]{2}{*}{ Week } & \multicolumn{7}{|c|}{ RT Mutations } \\
\hline & & $|3|$ & K64 & K65 & N69 & $\mathbf{R 8 2}$ & Al 58 & S2II \\
\hline \multirow[t]{4}{*}{ P5 12} & 2 & - & $\mathrm{R} / \mathrm{K}$ & $R$ & $\mathrm{~T}$ & $\mathrm{~K}$ & S & $\mathrm{N} / \mathrm{S}$ \\
\hline & 6 & - & $\mathrm{R} / \mathrm{K}$ & $R$ & $\mathrm{~T}$ & $\mathrm{~K}$ & $S$ & $N$ \\
\hline & 35 & - & $\mathrm{R} / \mathrm{K}$ & $R$ & $\mathrm{~T}$ & $\mathrm{~K}$ & $S$ & $\mathrm{~N} / \mathrm{S}$ \\
\hline & 55 & - & $\mathrm{R}$ & $R$ & $\mathrm{~T}$ & $\mathrm{~K}$ & $S$ & $\mathrm{~N} / \mathrm{S}$ \\
\hline \multirow[t]{4}{*}{ P679 } & 2 & - & $R / K$ & $\mathrm{R}$ & $\mathrm{T}$ & $\mathrm{K}$ & $S$ & - \\
\hline & 23 & - & $R / K$ & $R$ & $\mathrm{~T}$ & $\mathrm{~K}$ & S & - \\
\hline & 35 & - & $\mathrm{R}$ & $\mathrm{R}$ & $\mathrm{T}$ & $\mathrm{K}$ & $S$ & $\mathrm{~N}$ \\
\hline & 55 & - & $\mathrm{R}$ & $R$ & $\mathrm{~T}$ & $\mathrm{~K}$ & $S$ & $\mathrm{~N} / \mathrm{S}$ \\
\hline \multirow[t]{3}{*}{ P804 } & 2 & - & $\mathrm{R} / \mathrm{K}$ & $\mathrm{R}$ & $\mathrm{T}$ & $\mathrm{K}$ & $S$ & $\mathrm{~N}$ \\
\hline & 11 & - & $\mathrm{R}$ & $R$ & $\mathrm{~T}$ & $\mathrm{~K}$ & $S$ & $\mathrm{~N}$ \\
\hline & 35 & - & - & - & $\mathrm{T}$ & $\mathrm{K}$ & S & $\mathrm{N} / \mathrm{S}$ \\
\hline \multirow[t]{4}{*}{ P806 } & 2 & - & - & $R$ & $\mathrm{~T}$ & $\mathrm{~K}$ & $S$ & $\mathrm{~N} / \mathrm{S}$ \\
\hline & 11 & $\mathrm{~V} / \mathrm{I}$ & - & $\mathrm{R}$ & $\mathrm{T}$ & $\mathrm{K}$ & $S$ & $\mathrm{~N} / \mathrm{S}$ \\
\hline & 35 & $\mathrm{~V}$ & $\mathrm{R} / \mathrm{K}$ & $R$ & $\mathrm{~T}$ & $\mathrm{~K}$ & $S$ & $\mathrm{~N} / \mathrm{S}$ \\
\hline & 55 & $\mathrm{~V}$ & $\mathrm{R} / \mathrm{K}$ & $R$ & $\mathrm{~T}$ & $\mathrm{~K}$ & $S$ & $\mathrm{~N} / \mathrm{S}$ \\
\hline
\end{tabular}



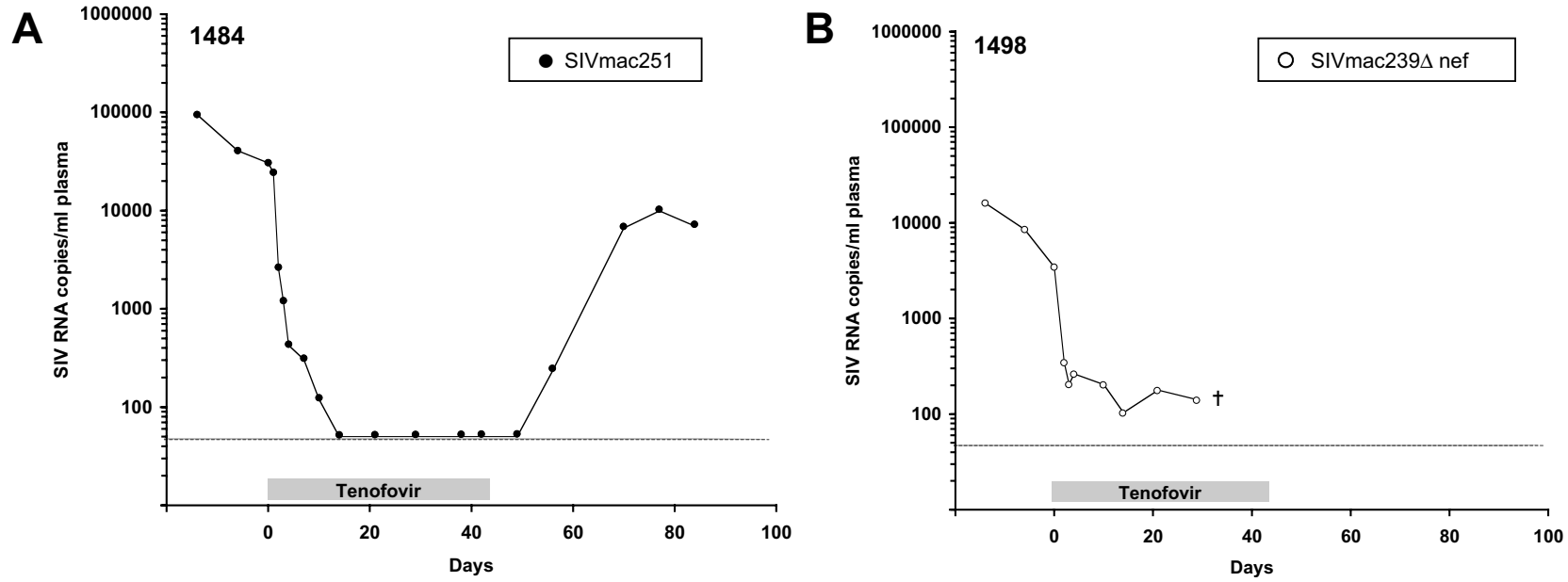

\section{Figure 3}

Effect of tenofovir on plasma viral load in macaques infected with SIVmac25 I or SIVmac239 $\Delta$ nef. Rhesus macaques with chronic SIV infection were treated for 6 weeks with tenofovir at a dose of $30 \mathrm{mg} / \mathrm{kg}$ body weight. The effect on SIV replication was determined by quantification of plasma SIV RNA by allele-specific real-time PCR. Plasma viral load is expressed as SIV RNA copies/ml and shown for macaques with replicating (A) SIVmac25I and (B) SIVmac239 2 nef.

lenge with SIVmac055. Unexpectedly, one of the tenofovir-treated animals (1498) died within hours of the SIVmac055 challenge. Autopsy revealed severe hepatic degeneration consistent with an idiosyncratic drug reaction to tenofovir and reduced clearance of the anesthetics.

The two remaining tenofovir-treated animals (1488 and $1514)$ continued to receive daily drug treatment for an additional 2 weeks after SIVmac055 challenge with no adverse events. In these macaques, SIVmac055 RNA was undetectable and remained so throughout a year of follow-up. Several blips of viremia occurred, and analyses of both viral RNA and DNA demonstrated persistence of nef deletions and pol sequences consistent with SIVmac239Anef (Fig. 4). We were unable to generate PCR amplicons containing either wild-type nef or SIVmac055 pol sequences despite multiple attempts using different peripheral blood samples from these macaques (Table 3 ). While CD4+ T cells transiently dropped in both macaques during tenofovir treatment, cell counts recovered after treatment and remained within the normal range throughout follow-up (Fig. 5A). Both animals remained healthy for more than three years after SIVmac055 challenge, at which time the study was completed.

\section{SIV-specific immune responses}

SIV-specific antibodies and $\mathrm{CD}^{+} \mathrm{T}$ cell responses were evaluated in both tenofovir-treated and control macaques before and after challenge with SIVmac055. Antibodies to both SIV gp130 and p27 antigens were detected in all ani- mals prior to SIVmac055 challenge. Titers of anti-gp130 antibodies did not change significantly in any of the macaques as a consequence of tenofovir treatment and similar patterns of responses were seen in both treated and control animals (Fig. 5B). Antibody titers to SIV gp130 varied by up to $1 \log _{10}$ among the macaques, but these differences were not associated with tenofovir treatment, viral load, or clinical outcome following SIVmac055 challenge.

Antibody titers to SIV p27 were lower overall as compared to gp130 antibody titers, but again showed no consistent relationship to tenofovir treatment. A transient drop in anti-p27 antibodies occurred in all the macaques following SIVmac055 challenge, but these titers subsequently increased to pre-challenge levels and were not clearly associated with adverse outcome (Fig. 5C).

SIV-specific CD8 ${ }^{+} \mathrm{T}$ cell responses were also assessed in the tenofovir-treated $(1488,1514)$ and untreated (1494, 1512) macaques (Table 4). ELISPOT assays were used to measure IFN- $\gamma$ secretion using recombinant vaccinia virus (rVV)-vectors expressing SIV Gag, Pol, Env and Nef proteins [25]. Macaque peripheral blood mononuclear cells (PBMC) were assayed at baseline (day -35), two weeks after initiation of tenofovir treatment (day -15) and 9 days after challenge with SIVmac055 (day 9) (Table 4). The number of spot-forming cells (SFC) to SIV antigens initially increased in 3 of 4 macaques during the period spanning tenofovir treatment (day -35 to day -15), but these 

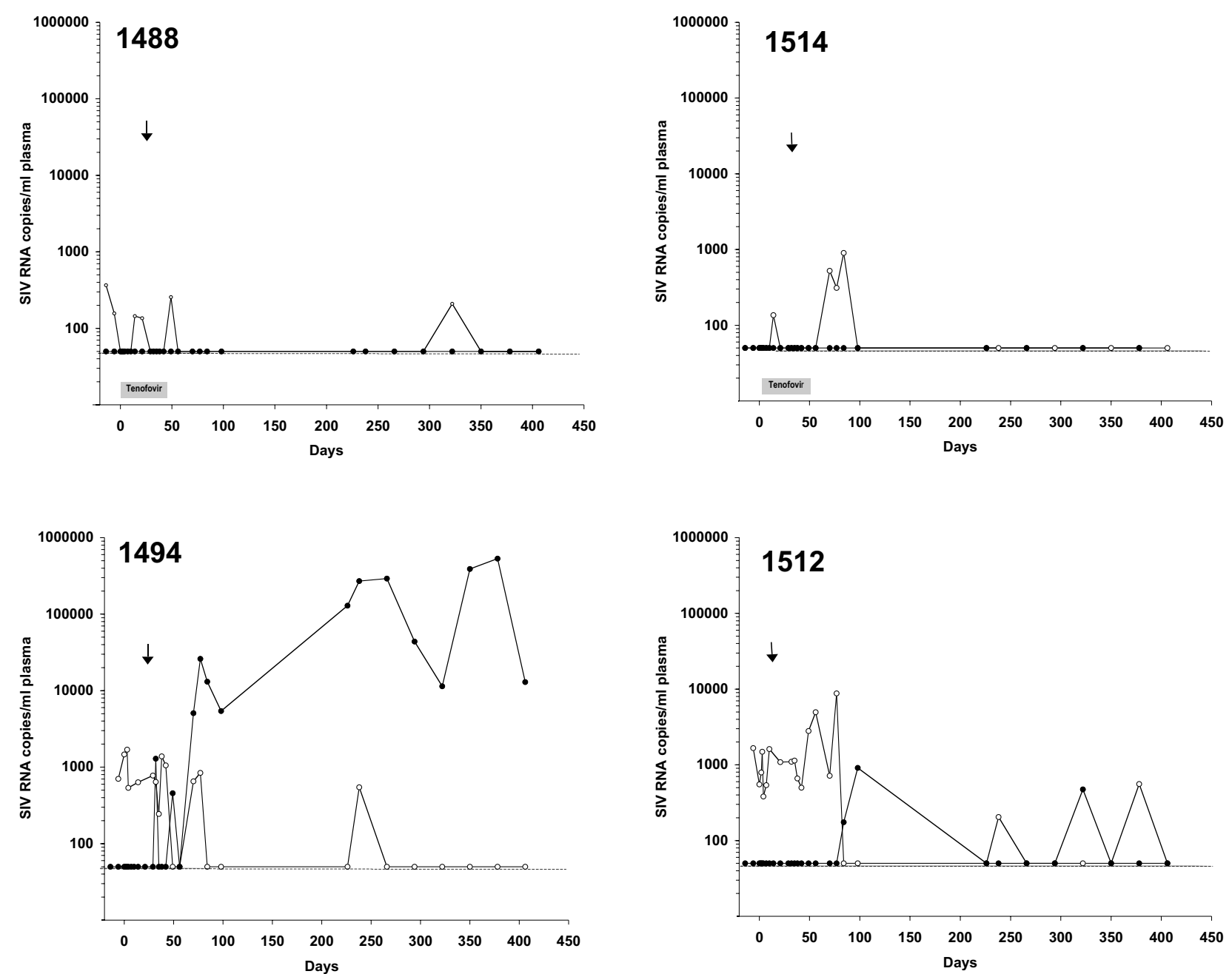

Figure 4

Replication of SIVmac055 in tenofovir-treated and untreated macaques infected with SIVmac239 $\Delta$ nef. Macaques chronically infected with SIVmac239 $\Delta$ nef were treated for 4 weeks with tenofovir (I488, I5I4) or left untreated ( 1494, I 5 I 2). Both treated and untreated macaques were challenged with SIVmac055 on day 28 (arrow). Replication of SIV was measured by allele-specific PCR to discriminate between SIVmac055 (O) and SIVmac239 0 nef (O). Data is expressed as SIV RNA copies/ml of plasma.

increases were observed for both tenofovir-treated (1488, 1514) and untreated (1494) macaques. SFC generally decreased following SIVmac055 challenge (day -15 to day 9) but again no consistent differences were observed between tenofovir-treated and control animals. During long-term follow-up, two protected macaques (1488, 1514) and one unprotected macaque that controlled SIVmac055 replication (1512) experienced an increase in the number of SFC approximately nine months after the challenge with SIVmac055 (day 265). The remaining untreated macaque (1494), which developed AIDS within
2 years after SIVmac055 challenge, experienced a decrease in $\mathrm{CD}^{+} \mathrm{T}$ cell responses at nine months.

Overall, macaques infected with SIVmac2394nef exhibited SIV-specific antibodies and $\mathrm{CD}^{+} \mathrm{T}$ cell responses to multiple viral antigens. However, these responses did not differ significantly between tenofovir-treated and untreated animals. While we were unable to assay for functional neutralizing antibodies and cytotoxic T lymphocyte (CTL) responses in this study due to sample limitations, we have previously shown that macaques 
A
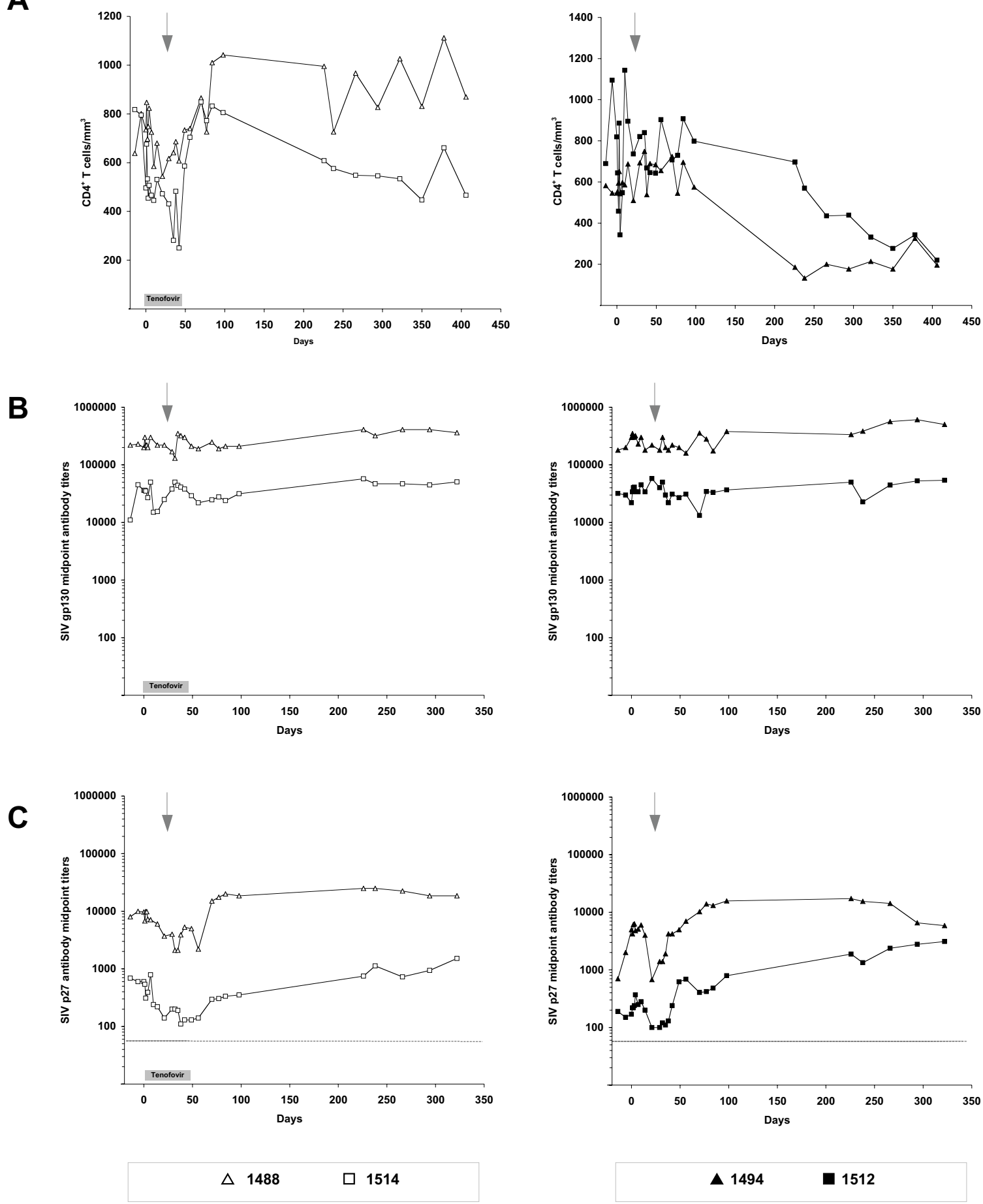

Figure 5

$\mathrm{CD4}^{+} \mathrm{T}$ cell counts and SIV-specific antibody responses in tenofovir-treated and untreated macaques infected with SIVmac239 $\Delta$ nef. Tenofovir-treated $(1488,1514)$ and untreated $(1494,1512)$ macaques infected with SIVmac239 $\Delta$ nef were challenged intravenously with SIVmac055 and monitored for (A) CD4 ${ }^{+} \mathrm{T}$ cell counts, (B) SIV gPI 30 antibody responses, and (C) SIV P27 antibody responses for approximately one year. Tenofovir treatment was given on days $0-42$. Intravenous inoculation of SIVmac055 occurred on day 28 (arrow). 
Table 3: Detection of SIVmac239 $\Delta$ nef and SIVmac055 following challenge with SIVmac055

\begin{tabular}{|c|c|c|c|c|c|c|c|c|c|c|c|c|}
\hline \multirow[b]{2}{*}{$\begin{array}{c}\text { Macaqu } \\
\text { e }\end{array}$} & \multirow[b]{2}{*}{ gene } & \multicolumn{11}{|c|}{ Weeks after challenge with SIVmac055 } \\
\hline & & $\mathbf{I}$ & 2 & 6 & 7 & 10 & 29 & 33 & 37 & 41 & 45 & $4 I^{\mathrm{a}}$ \\
\hline \multirow[t]{2}{*}{1494} & pol & 239 & 239 & 055 & 055 & 239 & 239 & 239 & 239 & 239 & 239 & 239 \\
\hline & nef & $\Delta$ nef & $\Delta$ nef & wt & wt & $w t$ & wt & $w t$ & wt & wt & wt & wt \\
\hline \multirow[t]{2}{*}{1512} & pol & & 239 & & & 055 & 055 & 055 & 055 & 055 & 055 & \\
\hline & nef & & $\Delta$ nef & & & $w t$ & $w t$ & $w t$ & wt & wt & wt & \\
\hline \multirow[t]{2}{*}{1488} & pol & 239 & 239 & & & & & 239 & & & & \\
\hline & nef & $\Delta$ nef & $\Delta$ nef & & & & & $\Delta$ nef & & & & \\
\hline \multirow[t]{2}{*}{1514} & pol & 239 & & & & 239 & & 239 & & & & \\
\hline & nef & $\Delta$ nef & & & & $\Delta$ nef & & $\Delta$ nef & & & & \\
\hline
\end{tabular}

a Cloned 7 kb fragment

infected with SIVmac239 $\Delta$ nef develop both SIV-specific neutralizing antibodies [16] and functional $\mathrm{CD}^{+} \mathrm{T}$ cell responses [17], and these responses may persist over time.

\section{Discussion}

The results of this study provide further support for the concept that antiretroviral drug treatment augmented by virus-specific immunity can prevent replication of drugresistant virus during chronic SIV infection. The animals used in this study were previously found to have robust and broadly reactive SIV-specific immune responses induced by infection with live, attenuated SIV [16]. These animals remained clinically healthy and intermittently viremic for several years with low-level replication of SIVmac239 $\Delta$ nef, thus providing an opportunity to evaluate the impact of drug treatment and suppression of drugresistant virus in macaques with chronic SIV infection.

Tenofovir has been shown to mediate potent and durable suppression of virulent SIV in both adult and neonatal macaques [20,21,23,26-32]. When administered early during the acute phase of SIV infection, macaques treated with tenofovir have significantly reduced viremia and improved clinical survival as compared to untreated animals [12]. The impact of tenofovir in suppressing viral replication is due in part to the synergistic action of $\mathrm{CD}^{+}$ T cells, which control replication of SIV during both acute and chronic phases of infection [17,33,34], suggesting that antiviral immunity plays a key role in determining the success of antiretroviral drugs [14]. Interestingly, when $\mathrm{CD}^{+} \mathrm{T}$ cells are depleted in vivo in macaques on long-term tenofovir therapy, viral rebound is associated with the presence of SIV variants harboring drug resistance mutations and reduced sensitivity to tenofovir [14], suggesting that antiviral immunity can suppress replication of drug-resistant virus.
Our results are consistent with this observation in macaques with strong anti-viral immune responses induced by chronic infection with live, attenuated SIV. Previously we demonstrated that in vivo depletion of $\mathrm{CD}^{+} \mathrm{T}$ cells in macaques infected with SIVmac239 $\Delta$ nef results in an increase in viremia, which is temporally controlled with restoration of the $\mathrm{CD} 8^{+} \mathrm{T}$ cell population, thus supporting the role of these cells in suppressing endogenous virus replication [17]. Furthermore, we have shown that this transient increase in endogenous SIV antigenaemia can enhance virus-specific immunity and is associated with protection from virulent SIVmac055 challenge [35]. In the present study, we found that SIV-specific immune responses in macaques chronically infected with SIVmac239 $\Delta$ nef were alone unable to prevent replication of drug-resistant SIVmac055 in untreated macaques. This may be due in part to waning of SIV-specific immune responses over time coupled with ongoing replication of live, attenuated SIV with increased pathogenicity [36].

But when combined with a short-course of tenofovir, replication of SIVmac055 was inhibited, suggesting that antiviral immunity can be effective when acting in concert with ART to suppress replication of drug-resistant virus. The macaques in this study were treated with tenofovir for 4 weeks prior to challenge with drug-resistant SIV. While tenofovir has direct antiviral effects against SIV through potent inhibition of the viral RT, it is also known to stimulate secretion of a number of immunomodulatory cytokines and chemokines, including interleukin-1 $\beta$ (IL$1 \beta)$, IL-10, tumor necrosis factor- $\alpha$, RANTES and macrophage inflammatory protein-1 $\alpha[37,38]$. These factors have both inhibitory and stimulatory effects on HIV-1 replication [39], in addition to their role in regulating immune cell function. Treatment with tenofovir may, therefore, augment antiviral immunity by stimulating 
Table 4: SIV-specific CD8 ${ }^{+} \mathrm{T}$ cell responses before and after SIVmac055 challenge

\begin{tabular}{|c|c|c|c|c|c|c|}
\hline Macaque & Daya & SIVenv & SIVgagb & SIVpolb & SIVnef & Tenofovirc \\
\hline \multirow[t]{4}{*}{1494} & $(-35)$ & 60 & 240 & 155 & 95 & No \\
\hline & $(-15)$ & 160 & 520 & 220 & 205 & \\
\hline & 9 & 45 & 255 & 115 & 120 & \\
\hline & 265 & 35 & 180 & 40 & 90 & \\
\hline \multirow[t]{4}{*}{1512} & $(-35)$ & 30 & 290 & 190 & 50 & No \\
\hline & $(-15)$ & 25 & 105 & 115 & 35 & \\
\hline & 9 & 40 & 95 & 60 & 15 & \\
\hline & 265 & 475 & 545 & 440 & 349 & \\
\hline \multirow[t]{4}{*}{1488} & $(-35)$ & 620 & 170 & 10 & 50 & Yes \\
\hline & $(-15)$ & 2365 & 510 & 70 & 80 & \\
\hline & 9 & 1533 & 458 & 83 & 168 & \\
\hline & 265 & 3305 & 1335 & 205 & 160 & \\
\hline \multirow[t]{4}{*}{1514} & $(-35)$ & 85 & 190 & 15 & 15 & Yes \\
\hline & $(-15)$ & 245 & 380 & 60 & 30 & \\
\hline & 9 & 65 & 85 & 25 & 0 & \\
\hline & 265 & 265 & 535 & 55 & 70 & \\
\hline
\end{tabular}

aDays before and after SIVmac055 challenge

bData is expressed as the number of spot-forming cells (SFC) per $10^{6}$ PBMC

cTenofovir treatment for a total of 6 weeks at a dose of $30 \mathrm{mg} / \mathrm{kg}$ of body weight

immunomodulatory factors and creating an environment less permissive for replication of drug-resistant strains, particularly those with reduced fitness compared to wildtype [5].

Our current findings suggest that replication of drugresistant SIVmac055, which harbors several resistance and compensatory mutations in RT, can be inhibited in immunocompetent animals receiving concurrent therapeutic intervention with tenofovir. SIVmac055 is an uncloned virus stock derived from an infant macaque infected with SIVmac251 and receiving long-term therapy with tenofovir and is therefore genotypically closely related to SIVmac251 [40]. This raises the question as to why the untreated macaques failed to prevent infection with SIVmac055, when they were previously protected from challenge with SIVmac251 [16]. One possible explanation is the presence of variants in the SIVmac055 stock that escape immune recognition due to mutations in $\mathrm{CD}^{+} \mathrm{T}$ cell epitopes. However, in untreated macaques that failed to be protected, replicating virus contained resistance mutations consistent with SIVmac055 indicating persistence of the drug-resistant genotype. It is known that cytotoxic T lymphocytes (CTL) from HIV-1 infected patients on antiretroviral therapy continue to respond in vitro to peptides containing drug resistance mutations $[9,41]$, and this may have contributed to control of SIVmac055 replication in the tenofovir-treated macaques, but may have been insufficient to block SIVmac055 replication in the untreated animals.

Tenofovir was withdrawn 2 weeks after SIVmac055 challenge in the treated macaques with no evidence of viral rebound, and only intermittent detection of SIVmac239 $\Delta$ nef, suggesting immune-mediated control of viremia is sustained in the absence of further drug intervention. No evidence was found for SIVmac055 infection in the tenofovir-treated macaques, in contrast to naïve control animals that received pre-exposure prophylaxis with tenofovir and experienced significant rebound of SIVmac055 viremia and clinical progression after drug was withdrawn. Taken together, these data indicate that SIVmac055 is able to infect and replicate in the presence of tenofovir during primary infection, and immune control of viremia is not sustained when drug is withdrawn. Similarly, macaques infected with SIVmac239 $\Delta$ nef that developed SIV-specific immune responses, but were not treated with tenofovir, were unable to prevent infection and replication of SIVmac055 indicating that antiviral immunity alone is insufficient to suppress drug-resistant SIV. Only those macaques that had both demonstrable antiviral immunity to SIV and short-term tenofovir treatment were able to prevent SIVmac055 infection, and these animals sustained low levels of viremia with SIVmac239 $\Delta$ nef for over three years after the drug was withdrawn.

\section{Conclusion}

In humans, potent suppression of chronic HIV-1 replication is achieved through therapeutic administration of antiretroviral drugs, which can reduce viremia often to undetectable levels for sustained periods, and can lead to partial restoration of $\mathrm{CD} 4^{+} \mathrm{T}$ cells and immune function [1-3]. The extent to which antiviral immune responses suppress the emergence of drug-resistant HIV-1 in humans in vivo is unknown, but our data in non-human 
primates support the idea that immune mechanisms contribute significantly to suppression of drug-resistant virus during chronic infection, and can augment the efficacy of ART. Strategies that seek to combine antiretroviral therapy with stimulation of HIV-1 specific immune responses [11], particularly CD8 $+\mathrm{T}$ cell responses, may be effective at treating HIV-1 infection and preventing therapeutic failure associated with the emergence of drug-resistant virus.

\section{Methods}

\section{Rhesus macaques}

A total of nine adult rhesus macaques (Macaca mulatta) were used in this study. Five were infected with SIVmac239 $\Delta$ nef (kindly provided by Dr. Ronald Desrosiers, New England Primate Research Center, Harvard Medical School, Southborough, MA) by intravenous inoculation of $4 \times 10^{3} 50 \%$ tissue-culture infective doses $\left(\mathrm{TCID}_{50}\right)$ as part of a larger vaccine study [16]. The animals were monitored for SIV-specific humoral and cellular immune responses, and for the ability to resist challenge with pathogenic SIVmac251 over a follow-up period of three years $[16,42]$. No evidence was found for infection with SIVmac251 in any of the animals based on repeated PCR evaluation of both peripheral blood mononuclear cells (PBMC) and lymph nodes [16], including analyses done immediately prior to initiation of this

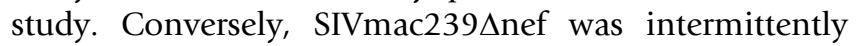
detected at low levels in all five macaques throughout the 3-year follow-up period. SIV-specific humoral and cellular immune responses were measured for each macaque to evaluate the correlates of immune protection associated with resistance to SIVmac251 challenge, and each of the macaques was found to have broad SIV-specific antibodies and $\mathrm{CD}^{+} \mathrm{T}$ cell responses [16].

Four naïve adult rhesus macaques were additionally used as controls to evaluate infection and replication of drugresistant SIVmac055. The control macaques were negative for type D retrovirus, and for SIV RNA and DNA prior to initiation of this study. All animal protocols were approved by the International Animal Care and Use Committee at the Tulane Regional Primate Research Center.

\section{Tenofovir treatment}

Control and SIV-infected rhesus macaques were treated with tenofovir (PMPA, kindly provided by Dr. Norbert Bischofsberger, Gilead Science, Foster City, CA) at a dose of $30 \mathrm{mg} / \mathrm{kg}$ per body weight for six weeks by daily subcutaneous injection.

\section{Drug-resistant SIVmac055}

SIVmac055 (kindly provided by Dr. Koen van Rompay, California Regional Primate Research Center, University of California, Davis, CA) was first isolated from an infant macaque infected with SIVmac251 and receiving pro- longed therapy with tenofovir. SIVmac055 exhibits a 5fold increased resistance to tenofovir in vitro associated with a K65R mutation in the viral reverse transcriptase $[20,40]$. A stock of SIVmac055 was prepared in rhesus PBMC and titered on $\mathrm{CEM} \times 174$ cells. Macaques were intravenously inoculated with $10^{4}$ TCID $_{50}$ of SIVmac055 and virus replication was monitored by real-time PCR and molecular beacons designed to differentially quantify SIVmac239 $\Delta$ nef and SIVmac055 RNA in plasma and PBMC as previously described [17].

To further investigate the genomic characteristics of replicating viruses, SIV pol and nef genes were analyzed by cloning and sequencing as described before [35].

\section{ELISPOT assay, ELISA, and flow cytometry}

The ELISPOT assay used for detection of IFN- $\gamma$ secretion by CD8 ${ }^{+} \mathrm{T}$ cells was modified from Larsson et al. [25] and previously described $[35,43]$. Antibodies to SIV gp130 and p27 in macaque plasma samples were detected by standard ELISA methods as described $[16,35]$. CD4 and CD8 T-cell subsets from whole blood collected in EDTA were analyzed by using anti-CD3 (Biosource International, Camarillo, CA), anti-CD4 and anti-CD8 (antiLeu3a and anti-Leu2a, respectively; Becton Dickinson, San Jose, CA) as previously described [16].

\section{Competing interests}

The author(s) declare that they have no competing interests.

\section{Authors' contributions}

KJM carried out SIV viral load quantification and sequence analyses, participated in the conception and design of the study, and drafted the manuscript. JMB carried out immunoassays for quantifying SIV antibody responses. AG coordinated all live animal work including tenofovir treatment and sample collection. PM participated in the conceptual design of the study. DFN conducted CD8 ${ }^{+} \mathrm{T}$ cell assays and participated in the design of the study. RIC participated in the design of the study and helped to draft the manuscript. All authors read and approved the final manuscript.

\section{Acknowledgements}

We wish to thank Frederick Lee, Walter Moretto, Sean Donahoe and Maciej Paluch for excellent technical assistance. We thank Lisa Chakrabarti and John Moore for their helpful comments and expertise. This work was funded by grants from the NIH (RR06555, Al43868), the Deutsche Forschungsgemeinschaft (SFB 466, Graduiertenkolleg I07I) and the Irene Diamond Fund. DFN is an Elizabeth Glaser scientist of the Elizabeth Glaser Pediatric AIDS Foundation.

\section{References}

I. Egger M, Hirschel B, Francioli P, Sudre P, Wirz M, Flepp M, Rickenbach $M$, Malinverni $R$, Vernazza $P$, Battegay $M$ : Impact of new antiretroviral combination therapies in HIV infected 
patients in Switzerland: prospective multicentre study. Swiss HIV Cohort Study. BMJ 1997, 3 I 5: I I94-I I 99.

2. Palella FJ Jr, Delaney KM, Moorman AC, Loveless MO, Fuhrer J, Satten GA, Aschman DJ, Holmberg SD: Declining morbidity and mortality among patients with advanced human immunodeficiency virus infection. HIV Outpatient Study Investigators. N Engl J Med I 998, 338:853-860.

3. Sterne JA, Hernan MA, Ledergerber B, Tilling K, Weber R, Sendi P, Rickenbach M, Robins JM, Egger M: Long-term effectiveness of potent antiretroviral therapy in preventing AIDS and death: a prospective cohort study. Lancet 2005, 366:378-384.

4. Phillips AN, Dunn D, Sabin C, Pozniak A, Matthias R, Geretti AM, Clarke J, Churchill D, Williams I, Hill T, et al.: Long term probability of detection of HIV-I drug resistance after starting antiretroviral therapy in routine clinical practice. AIDS 2005 , 19:487-494.

5. Barbour JD, Grant RM: The Role of Viral Fitness in HIV Pathogenesis. Curr HIVIAIDS Rep 2005, 2:29-34.

6. Buckheit RW Jr: Understanding HIV resistance, fitness, replication capacity and compensation: targeting viral fitness as a therapeutic strategy. Expert Opin Investig Drugs 2004, I 3:933-958.

7. Shet A, Markowitz M: Transmitted multidrug resistant HIV-I: new and investigational therapeutic approaches. Curr Opin Investig Drugs 2006, 7:709-720.

8. Turner $D$, Wainberg MA: HIV transmission and primary drug resistance. AIDS Rev 2006, 8: 17-23.

9. Mason RD, Bowmer MI, Howley CM, Gallant M, Myers JC, Grant MD: Antiretroviral Drug Resistance Mutations Sustain or Enhance CTL Recognition of Common HIV-I Pol Epitopes. J Immunol 2004, I 72:72। 2-72I9.

10. Stratov I, Dale CJ, Chea S, McCluskey J, Kent S]: Induction of T-cell immunity to antiretroviral drug-resistant human immunodeficiency virus type I. J Virol 2005, 79:7728-7737.

11. Shehu-Xhilaga M, Tachedjian G, Crowe SM, Kedzierska K: Antiretroviral compounds: mechanisms underlying failure of HAART to eradicate HIV-I. Curr Med Chem 2005, I 2: I 705- 1719.

12. Van Rompay KK: Antiretroviral drug studies in nonhuman primates: a valid animal model for innovative drug efficacy and pathogenesis experiments. AIDS Rev 2005, 7:67-83.

13. Taber R, Rajakumar PA, Fuller DH, Trichel AM, Dowling P, Meleason $D$, Amedee A, Murphey-Corb M: Effects of monotherapy with (R)-9-(2-phosphonylmethoxypropyl)adenine (PMPA) on the evolution of a primary Simian immunodeficiency virus (SIV) isolate. Virology 2006, 354: I| $6-131$.

14. Van Rompay KKA, Singh RP, Pahar B, Sodora DL, Wingfield C, Lawson JR, Marthas ML, Bischofberger N: CD8+-Cell-Mediated Suppression of Virulent Simian Immunodeficiency Virus during Tenofovir Treatment. J Virol 2004, 78:5324-5337.

15. Koff WC, Johnson PR, Watkins DI, Burton DR, Lifson JD, Hasenkrug $\mathrm{KJ}$, McDermott $A B$, Schultz A, Zamb TJ, Boyle R, et al.: HIV vaccine design: insights from live attenuated SIV vaccines. Nat Immunol 2006, 7:19-23.

16. Connor RI, Montefiori DC, Binley JM, Moore JP, Bonhoeffer S, Gettie A, Fenamore EA, Sheridan KE, Ho DD, Dailey PJ, et al.: Temporal analyses of virus replication, immune responses, and efficacy in rhesus macaques immunized with a live, attenuated simian immunodeficiency virus vaccine. J Virol 1998, 72:750I-7509.

17. Metzner KJ, Jin X, Lee FV, Gettie A, Bauer DE, Di Mascio M, Perelson AS, Marx PA, Ho DD, Kostrikis LG, et al:: Effects of in vivo CD8(+) $T$ cell depletion on virus replication in rhesus macaques immunized with a live, attenuated simian immunodeficiency virus vaccine. I Exp Med 2000, 191:1921-1931.

18. Baba TW, Jeong YS, Pennick D, Bronson R, Greene MF, Ruprecht RM: Pathogenicity of live, attenuated SIV after mucosal infection of neonatal macaques. Science 1995, 267:1820-1825.

19. Baba TW, Liska V, Khimani AH, Ray NB, Dailey PJ, Penninck D, Bronson R, Greene MF, McClure HM, Martin LN, et al.: Live attenuated, multiply deleted simian immunodeficiency virus causes AIDS in infant and adult macaques. Nat Med 1999, 5:194-203.

20. Van Rompay KK, Cherrington JM, Marthas ML, Berardi C], Mulato AS, Spinner A, Tarara RP, Canfield DR, Telm S, Bischofberger N, et al: 9[2-(Phosphonomethoxy)propyl]adenine therapy of established simian immunodeficiency virus infection in infant rhesus macaques. Antimicrob Agents Chemother 1996, 40:2586-2591.

21. Tsai CC, Follis KE, Sabo A, Beck TW, Grant RF, Bischofberger N, Benveniste RE, Black R: Prevention of SIV infection in macaques by (R)-9-(2-phosphonylmethoxypropyl)adenine. Science 1995, 270: I197-1199.

22. Van Rompay KK, Berardi CJ, Aguirre NL, Bischofberger N, Lietman PS, Pedersen NC, Marthas ML: Two doses of PMPA protect newborn macaques against oral simian immunodeficiency virus infection. AIDS 1998, I 2:F79-F83.

23. Tsai CC, Follis KE, Beck TW, Sabo A, Bischofberger N, Dailey PJ: Effects of (R)-9-(2-phosphonylmethoxypropyl)adenine monotherapy on chronic SIV infection in macaques. AIDS Res Hum Retroviruses 1997, I3:707-7|2.

24. Regier DA, Desrosiers RC: The complete nucleotide sequence of a pathogenic molecular clone of simian immunodeficiency virus. AIDS Res Hum Retroviruses 1990, 6:122I-I23I.

25. Larsson M, Jin X, Ramratnam B, Ogg GS, Engelmayer J, Demoitie MA, McMichael AJ, Cox WI, Steinman RM, Nixon D, et al.: A recombinant vaccinia virus based ELISPOT assay detects high frequencies of Pol-specific CD8 T cells in HIV-I-positive individuals. AIDS 1999, 13:767-777.

26. Hodge S, de Rosayro J, Glenn A, Ojukwu IC, Dewhurst S, McClure HM, Bischofberger N, Anderson DC, Klumpp SA, Novembre F): Postinoculation PMPA treatment, but not preinoculation immunomodulatory therapy, protects against development of acute disease induced by the unique simian immunodeficiency virus SIVsmmPBj. J Virol 1999, 73:8630-8639.

27. Lifson JD, Piatak M Jr, Cline AN, Rossio JL, Purcell J, Pandrea I, Bischofberger N, Blanchard J, Veazey RS: Transient early postinoculation anti-retroviral treatment facilitates controlled infection with sparing of CD4+ T cells in gut-associated lymphoid tissues in SIVmac239-infected rhesus macaques, but not resistance to rechallenge. J Med Primatol 2003, 32:20I-2I0.

28. Rosenwirth B, ten Haaft P, Bogers WM, Nieuwenhuis IG, Niphuis H, Kuhn EM, Bischofberger N, Heeney JL, Uberla K: Antiretroviral therapy during primary immunodeficiency virus infection can induce persistent suppression of virus load and protection from heterologous challenge in rhesus macaques. J Virol 2000, 74: I704- I7II.

29. Silvera P, Racz P, Racz K, Bischofberger N, Crabbs C, Yalley-Ogunro J, Greenhouse J, Jiang JB, Lewis MG: Effect of PMPA and PMEA on the kinetics of viral load in simian immunodeficiency virusinfected macaques. AIDS Res Hum Retroviruses 2000, 16:791-800.

30. Tarantal AF, Marthas ML, Shaw JP, Cundy K, Bischofberger N: Administration of 9-[2-(R)-(phosphonomethoxy)propyl]adenine (PMPA) to gravid and infant rhesus macaques (Macaca mulatta): safety and efficacy studies. J Acquir Immune Defic Syndr Hum Retrovirol 1999, 20:323-333.

3I. Van Rompay KK, Dailey PJ, Tarara RP, Canfield DR, Aguirre NL, Cherrington JM, Lamy PD, Bischofberger N, Pedersen NC, Marthas ML: Early short-term 9-[2-(R)-(phosphonomethoxy)propyl]adenine treatment favorably alters the subsequent disease course in simian immunodeficiency virus-infected newborn Rhesus macaques. J Virol 1999, 73:2947-2955.

32. Van Rompay KK, Singh RP, Brignolo LL, Lawson JR, Schmidt KA, Pahar B, Canfield DR, Tarara RP, Sodora DL, Bischofberger N, et al.: The clinical benefits of tenofovir for simian immunodeficiency virus-infected macaques are larger than predicted by its effects on standard viral and immunologic parameters. Acquir Immune Defic Syndr 2004, 36:900-914.

33. Jin X, Bauer DE, Tuttleton SE, Lewin S, Gettie A, Blanchard J, Irwin CE, Safrit JT, Mittler J, Weinberger L, et al.: Dramatic rise in plasma viremia after CD8(+) $\mathrm{T}$ cell depletion in simian immunodeficiency virus-infected macaques. J Exp Med 1999, 189:991-998.

34. Schmitz JE, Kuroda MJ, Santra S, Sasseville VG, Simon MA, Lifton MA, Racz P, Tenner-Racz K, Dalesandro M, Scallon BJ, et al.: Control of viremia in simian immunodeficiency virus infection by CD8+ lymphocytes. Science 1999, 283:857-860.

35. Metzner KJ, Moretto WJ, Donahoe SM, Jin X, Gettie A, Montefiori DC, Marx PA, Binley JM, Nixon DF, Connor RI: Evaluation of CD8+ T-cell and antibody responses following transient increased viraemia in rhesus macaques infected with live, attenuated simian immunodeficiency virus. J Gen Virol 2005, 86:3375-3384.

36. Hofmann-Lehmann R, Vlasak J, Williams AL, Chenine AL, McClure HM, Anderson DC, O'Neil S, Ruprecht RM: Live attenuated, nefdeleted SIV is pathogenic in most adult macaques after prolonged observation. AIDS 2003, 17:157-166. 
37. Zidek Z, Holy A, Frankova D: Antiretroviral agent (R)-9-(2phosphonomethoxypropyl)adenine stimulates cytokine and nitric oxide production. Eur J Pharmacol 1997, 33 I:245-252.

38. Zidek Z, Frankova D, Holy A: Activation by 9-(R)-[2-(phosphonomethoxy)propyl]adenine of chemokine (RANTES, macrophage inflammatory protein Ialpha) and cytokine (tumor necrosis factor alpha, interleukin-10 [IL-10], IL-Ibeta) production. Antimicrob Agents Chemother 2001, 45:338I-3386.

39. Kedzierska K, Crowe SM: Cytokines and HIV-I: interactions and clinical implications. Antivir Chem Chemother 200I, I 2:133-I50.

40. Van Rompay KK, Cherrington JM, Marthas ML, Lamy PD, Dailey PJ, Canfield DR, Tarara RP, Bischofberger N, Pedersen NC: 9-[2(Phosphonomethoxy)propyl]adenine (PMPA) therapy prolongs survival of infant macaques inoculated with simian immunodeficiency virus with reduced susceptibility to PMPA. Antimicrob Agents Chemother 1999, 43:802-8I2.

4I. Schmitt M, Harrer E, Goldwich A, Bauerle M, Graedner I, Kalden IR, Harrer T: Specific recognition of lamivudine-resistant HIV-I by cytotoxic T lymphocytes. AIDS 2000, 14:653-658.

42. Nixon DF, Donahoe SM, Kakimoto WM, Samuel RV, Metzner KJ Gettie A, Hanke T, Marx PA, Connor RI: Simian immunodeficiency virus-specific cytotoxic $T$ lymphocytes and protection against challenge in rhesus macaques immunized with a live attenuated simian immunodeficiency virus vaccine. Virology 2000, 266:203-210.

43. Moretto WJ, Drohan LA, Nixon DF: Rapid quantification of SIVspecific CD8 $T$ cell responses with recombinant vaccinia virus ELISPOT or cytokine flow cytometry. AIDS 2000, 14:2625-2627.

Publish with Bio Med Central and every scientist can read your work free of charge

"BioMed Central will be the most significant development for disseminating the results of biomedical research in our lifetime. "

Sir Paul Nurse, Cancer Research UK

Your research papers will be:

- available free of charge to the entire biomedical community

- peer reviewed and published immediately upon acceptance

- cited in PubMed and archived on PubMed Central

- yours - you keep the copyright

Submit your manuscript here:

http://www.biomedcentral.com/info/publishing_adv.asp
BioMedcentral 